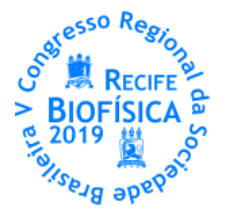

\title{
ATIVIDADE BRONCODILATADORA DO ÓLEO ESSENCIAL DE Lippia sidoides CHAM. EM BRONQUÍOLO ISOLADO DE SUs scrofa domesticus.
}

\author{
Luís Pereira-de-Morais ${ }^{2 *}$, Andressa de Alencar Silva², Renata Evaristo Rodrigues da Silva ${ }^{1}$, Débora de Menezes \\ Dantas $^{1}$, Nayane de Sousa Almeida ${ }^{1}$, Cícera Geórgia Brito Milfont ${ }^{1}$, Cicero Pedro da Silva Junior ${ }^{1}$, Isaac Moura \\ Araújo ${ }^{1}$, Roseli Barbosa ${ }^{1}$, José Henrique Leal-Cardoso ${ }^{2}$
}

\author{
${ }^{1}$ Laboratório de Fisiofarmacologia das Células Excitáveis, URCA; ${ }^{2}$ Laboratório de Eletrofisiologia, UECE \\ *luispereira256@gmail.com
} \begin{abstract}
INTRODUÇÃO
A espécie $L$ sidoides é um vegetal arbustivo, conhecida popularmente como alecrim-pimenta; suas folhas são grossoserreadas, com dimensões variáveis (aproximadamente até $8 \mathrm{~cm}$ ), revestidas de pêlos em ambas as faces (TEÓFILO, 2012); suas flores são de cor branco-amareladas, pequenas e encontram-se em inflorescências subglobosas e subpiramidais (CRAVEIRO et al., 1981). Encontrada em abundância no sertão nordestino, sendo mais comum nos estados do Ceará e Rio Grande do Norte. Boa parte dos espécimes do gênero Lippia são aromáticas e dentre elas se destaca L. sidoides por ser utilizada na medicina popular, principalmente como antisséptico (LACOSTE et al., 1996; LEMOS et al., 1990). Suas folhas são geralmente utilizadas de forma tópica, como remédios caseiros no tratamento de acne, ferimentos, infecções da pele e do couro cabeludo. Sua infusão tem sido usada na medicina popular como aromoterápico, para rinite alérgica e no tratamento das infecções vaginais, boca e garganta (MATOS; OLIVEIRA, 1998).
\end{abstract}

Várias ações biológicas da espécie $L$. sidoides que já estão documentadas na literatura, como: atividade antimicrobiana contra Staphylococcus aureus (SILVA et al., 2010), antifúngica em Curvularia luneta (DE SOUZA FERREIRA et al., 2018), inseticida em Rhodnius prolixus vetor da doença de Chagas (FIGUEIREDO et al., 2017), inibidor da excitabilidade nervosa em nervo ciático de ratos (BARBOSA et al., 2017), efeito antiespasmódico em traqueia de ratos (TEÓFILO, 2012).

Por possuir efeito miorrelaxante em musculatura de vias aéreas de animais de experimentação e devido à grande variabilidade de resposta do musculo traquealis de diferentes espécies animais a um dado agente biológico, procuramos evidenciar se a espécie $L$. sidoides apresenta esse mesmo efeito em vias aéreas provenientes de animais de abatedouro. $O$ uso de animais de abatedouro ao invés de animais laboratoriais, se apropriado cientificamente, é vantajoso pois melhor se adequa à regra dos 3 Rs (reduce, refine, replace). Esta regra foi iniciada pela federação das Universidades para o Bemestar Animal (The Universities Federation for Animal Welfare UFAW's), que significa reduzir o número de animais utilizados na pesquisa, refinar a metodologia de forma a diminuir a dor e desconforto sofrido por os mesmos, e buscar métodos alternativos que, por fim, substituam seu uso, sendo esta a meta máxima a ser alcançada (RUSSEL; BURCH, 1992).

Neste trabalho optou-se por utilizar como modelo altenativo, utilizando tecido brônquico de porcos da espécie Sus scrofa domesticus (Large Whit). O tecido provenientes de suínos se caracteriza como um método alternativo, uma vez, que os animais utilizados para extração dos bronquíolos são abatidos para comercialização de sua carne. Além disso, há uma semelhança da fisiologia e bioquímica do suíno com a dos seres humanos.

Nesse trabalho será avaliada a ação do óleo essencial de $L$. sidoides em músculo liso de bronquíolos de porcos. Este estudo tem por objetivo elucidar a ocorrência e aspectos quantitativos dos parâmetros da ação miorrelaxante do óleo essencial de Lippia sidóides sobre o musculo liso de bronquíolos de porcos e determinar os aspectos quantitativos dos parâmetros desta ação.

\section{MATERIAIS E MÉTODOS}

Segundo a resolução Normativa Concea $n^{\circ} 30$, de 02 de fevereiro de 2016 cadáveres ou parte deles oriundos das atividades de matadouros, frigoríficos, abatedouros ou produtores rurais para consumo, fica isento de passar pela a Comissão de uso e Experimentação Animal (CEUA) para que seja avaliado seus aspectos éticos.

Um total de 24 fragmentos de pulmões de porcos Sus scrofa domesticus, adultos, distribuídos em protocolos de 3 animais, que foram obtidos do abatedouro Frigorífico Industrial do Cariri, localizado em Juazeiro do Norte, Ceará, Brasil. 0 órgão foi provido de animais que foram abatidos para consumo de carne. Todos os animais assim como sua carne e vísceras foram inspecionados por médicos veterinários antes e depois do abate, constatando a sanidade do animal.

Durante o transporte para o laboratório, os pulmões foram colocados em solução gelada de Tyrode modificado (TM) com seguinte composição em mM: NaCl=136; $\mathrm{KCl}=5,0 ; \mathrm{MgCl}_{2}=0,98 ; \mathrm{NaH}_{2} \mathrm{PO}_{4}=0,36$; $\mathrm{NaHCO}_{3}=11,9 ; \mathrm{CaCl}_{2}=2.0$ e Glicose=5,5. O brônquio do tronco de um lobo inferior do pulmão foi dissecado e os ramos laterais foram retirados e colocados em TM.

Posteriormente foi feita a limpeza dos segmentos brônquicos e logo após cortados em anéis ( 3 a $5 \mathrm{~mm}$ de comprimento e 3 a $5 \mathrm{~mm}$ de diâmetro). Estes anéis foram horizontalmente suspenso entre dois ganchos de aço inoxidável em forma de $L$ e montados em banho para órgão isolado com capacidade para $10 \mathrm{~mL}$ de TM com contínua aeração, regulação da temperatura em $37^{\circ} \mathrm{C}$ e pH 7,4. Um dos ganchos de aço inoxidável foi conectado a um transdutor de força através de uma haste móvel, e o outro a uma base fixa do equipamento. Após a preparação, os segmentos isolados de bronquíolos foram submetidos a uma tensão de $1 \mathrm{gF}$ e estabilização mantida por um período de 1 hora com renovação do TM a cada 15 minutos, tempo necessário para a adaptação da preparação às novas condições.

Para avaliação do efeito do óleo essencial de Lippia sidoides, (OELs) e seu componente, foi obtido duas curvas concentração-resposta do 
agente contraturante $\mathrm{KCl}$ à $60 \mathrm{mM}(\mathrm{K} 60)$, provando a viabilidade do tecido. Em seguida, uma terceira contração tônica foi evocada com o agente contraturante apropriado para promover contração pelo acoplamento eletromecânico, o potássio $(\mathrm{KCl} 60 \mathrm{mM})$ ou acoplamento farmacomecânico, a ACh $(10 \mu \mathrm{M})$. Em seguida sobre essa tônica (terceira contração) foi acrescentada doses subsequentes e cumulativas do OELs, nas concentrações de: 1 - 3.000 $\mu \mathrm{g} / \mathrm{mL}$, em experimentos distintos, logo após foram realizadas lavagens sucessivas com TM afim de desimpregnar os agentes em estudo do tecido brônquico para posterior indução de contração com $\mathrm{K} 60 \mathrm{a}$ fim de observar a recuperação do tecido.

\section{RESULTADOS E DISCUSSÃO}

Para avaliar a influência do OELs, sobre contrações induzidas por $\mathrm{K}^{+} \mathrm{e} \mathrm{ACh}$ foi administrada concentrações crescentes e cumulativas de OELs $1-3000 \mu \mathrm{g} / \mathrm{mL}$, previamente contraídos por $\mathrm{KCl}$ $(60 \mathrm{mM})$ ou ACh $(10 \mu \mathrm{M})$.

Inicialmente, ao avaliar as contrações da musculatura lisa brônquica induzida por $\mathrm{KCl}$, verificamos que OELs foi capaz de relaxar a contração promovida por K60 de forma concentração dependente, promovendo inibição máxima (100\%) em 1000 de OELs (Figura $01 \mathrm{~A}$ ). Observou-se que, esse efeito ocorreu de forma estatisticamente significante a partir da concentração de $100 \mu \mathrm{g} / \mathrm{mL}$ de OELs ( $\mathrm{p}<0,001$, ANOVA, método Holm-Sidak). Os valores de $\mathrm{IC}_{50}$ obtidos nesta via eletromecânica foi de: $450,49 \pm 5,73 \mu \mathrm{g} / \mathrm{mL}$ ( $\mathrm{p}<$ 0,05, ANOVA, método Bonferroni).

Nas contrações promovidas pela acetilcolina $10 \mu \mathrm{M}$, verificou-se que o OELs, não inibiu $100 \%$ mesmo com $3000.0 \mu \mathrm{g} / \mathrm{mL}$ (Figura 01 B). O relaxamento promovido pelo OELs na via farmacomecânica foi estatisticamente significante apenas para as concentrações de 600,1000 e $3000 \mu \mathrm{g} / \mathrm{mL}$, sendo: $15,14 \pm 8,23$, $20,15 \pm 9,88,30,39 \pm 10,51 \%$, respectivamente $(p<0,001$, ANOVA, método Holm-Sidak). Não foi possível determinar-se o valor de $\mathrm{IC}_{50}$. O principal achado desta pesquisa foi que o OELs conseguiu inibir de forma significativa as contrações dos tecidos brônquicos dos suínos induzidas por $\mathrm{KCl}$. Entretanto o mesmo não observado com igual intensidade nas contrações estimuladas pelo mecanismo da ACh. Por tanto do ponto de vista farmacodiâmico, o OELs pode ser considerado um agente miorrelaxante que atua principalmente (com maior potência farmacológica) através de mecanismo inespecífico, possivelmente bloqueio de canais de $\mathrm{Ca}^{2+}$ dependente de voltagem. Esses resultados mostraram-se reversíveis com a lavagem desse agente, evidenciando que o efeito apresentado não está relacionado com um efeito tóxico letal ao tecido.

Em estudos anteriores foram relatadas atividade miorrelaxante de outras espécies do gênero Lippia (SILVA et al., 2018; BLANCO et al., 2013 ).

Os resultados obtidos corroboram os dados encontrados por Carvalho et al. (2018) onde foram testados o óleo essencial de Lippia alba e seus constituintes isolados, evidenciando relaxamento das contrações provocadas pela via eletromecânica $(\mathrm{K}+)$ em contraste com o baixa eficiência no relaxamento das contrações provocadas pela via do acoplamento farmacomecânico (ACh). Em vista disso, sugere-se que a atividade observada está relacionada ao bloqueio dos canais iônicos dependentes de voltagem.

Esse estudo evidenciou atividade relaxante do OELs no tecido respiratório de S. scrofa domesticus. Dada a semelhança fisiológica do trato respiratório suínos com o dos seres humanos, sugere-se que - OELs tenha potencial farmacológico para o combate a doenças do trato respiratório. No entanto, se fazem necessários outros estudos para compreender melhor os mecanismos envolvidos, bem como avaliar outras possíveis vias farmacológicas e/ou eletromecânica.
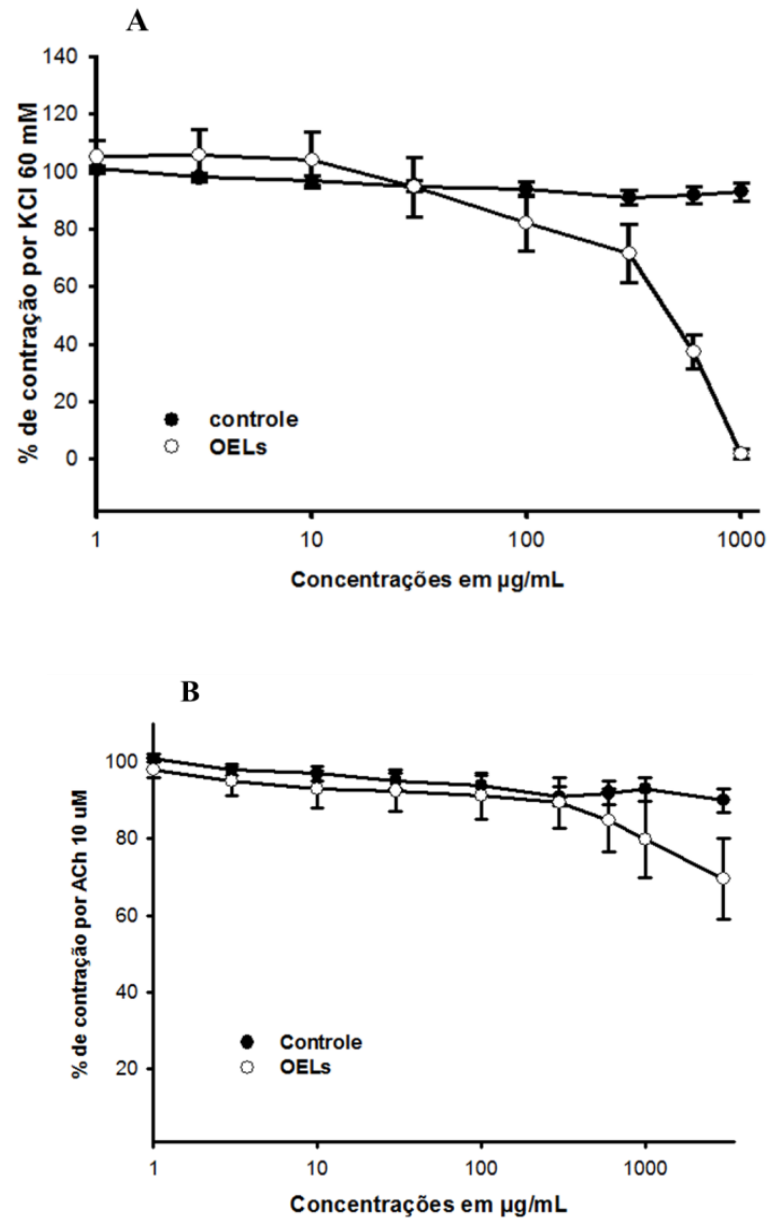

Figura 1. Efeito relaxante do OELs em concentrações mantidas por potássio e acetilcolina em tecido brônquico de S. scrofa domesticus. (A) Curva concentração-efeito de OELs, (1 $1000 \mu \mathrm{g} / \mathrm{mL})$, sob contração induzida por $\mathrm{KCl}(60 \mathrm{mM})$ em bronquíolos isolados de suíno. (B) Curva concentração-efeito de OELS $(1-3000 \mu \mathrm{g} / \mathrm{mL})$ sob contração provocadas por ACh $(10 \mu \mathrm{M})$ em bronquíolos isolados de suíno. Os valores são expressos como média \pm S.E.M ( $p<0,05$, one-way ANOVA seguido por Holm-Sidak), onde $N$ representa o número de experimentos.

\section{CONCLUSÕES}

Os resultados mostram que o OELs, possui efeito miorrelaxante em tecido brônquico de suíno. Os dados sugerem que este efeito pode ser mediado por canais iônicos presentes na membrana, pois OELs reverte as contrações induzidas pelo potássio, inibindo-as com potência farmacológica maior do aquela evidenciada para o bloqueio das contrações induzidas pela $\mathrm{ACh}$. Os resultados também sugerem a potencialidade terapêutica do OELs para para terapêutica de doenças que afetam o sistema respiratório que envolvam brococonstricção, como no caso da asma e bronquites.

\section{REFERÊNCIAS}

Blanco M.A., Colareda, G.A., Van Baren, C., Bandoni, A.L., Ringuelet J., Consolini, A.E. 2013. Antispasmodic effects and composition of the essential oils from two South American chemotypes of Lippia alba, J. Ethnopharmacol. 149, 803-809.

BRITO, D. I. V. et al. Análise fitoquímica e atividade antifúngica do óleo essencial de folhas de Lippia sidoides Cham. e do Timol contra cepas de Candida spp. Rev. Bras. Plantas Med, v. 17, p. 836-844, 2015.

Carvalho, P. M.M., Macêdo, C. A.F., Ribeiro, T. F., Silva, A. A., Silva, R.E.R., Morais, L. P., Marta R. Kerntopfb , Menezes, I. R.A., Barbosa, R. 2018. Effect of the Lippia alba (Mill.) N.E. Brown essential oil and 
its main constituents, citral and limonene, on the tracheal smooth muscle of rats. Biotechnology Reports, 17. 31-34.

COSTA, S M O. et al. Constituintes químicos de Lippia sidoides (Cham.) Verbenaceae. Rev. bras. farmacogn., v.12, p. 66-67, 2002. CRAVEIRO, A. A. et al. Óleos essenciais de plantas do Nordeste. Fortaleza, CE: Edições UFC, 1981.

DE SOUZA FERREIRA, Talita Pereira et al. Enzymatic activity and elicitor of phytoalexins of Lippia sidoides Cham. and endophytic fungi. African Journal of Biotechnology, v. 17, n. 15, p. 521-530, 2018.

Devi, R.C., Sim, S.M., Ismail, R. 2011. Efeito espasmolítico de citral e extratos de Cymbopogon citratus no íleo de coelho isolado, J. Músculo. Liso. Res. 47, 143-156.

FIGUEIREDO, Marcela B. et al. Lethal and sublethal effects of essential oil of Lippia sidoides (Verbenaceae) and monoterpenes on Chagas' disease vector Rhodnius prolixus. Memórias do Instituto Oswaldo Cruz, v. 112, n. 1, p. 63-69, 2017.

LEMOS TLG. Et al. Antimicrobial activity of essential oils of brazilian plants. Phytoterapy Research.; v. 4: p. 82-4, 1990.

MATOS, F.J.A.; OLIVEIRA, F. Lippia sidoides Cham.-Farmacognosia, química e farmacologia. Revista Brasileira de Farmacognosia, v. 79, p. 84-87, 1998.

RUSSEL, W. M. S.; BURCH, R. L. The principles of humane experimental technique. London: Universities Federation for Animal Welfare (UFAW), 1992. ISBN: 0900767782. Special Edition. Disponível em: $<$ http:// altweb.jhsph.edu/publications/humane_exp/het-toc.htm>.

Silva, R.E.R., Morais, L.P., Silva, A.A., Bastos, C.M.S., PereiraGonçalves, Á., Kerntopf, M.R., Menezes, I.R.A., Leal-Cardoso, J.H., Barbosa, R. 2018. Vasorelaxant effect of the Lippia alba essential oil and its major constituent, citral, on the contractility of isolated rat aorta. Biomedicine \& Pharmacotherapy, 108, 792-798.

SILVA, V.A. et al . Avaliação in vitro da atividade antimicrobiana do extrato da Lippia sidoides Cham. sobre isolados biológicos de Staphylococcus aureus. Revista brasileira de plantas medicinais, Botucatu, v. 12, n. 4,dez. 2010.

TEÓFILO, TMNG. "Efeito antiespasmódico do óleo essencial da " Lippia sidoides Cham. e seus constituíntes, timol, para-cimeno e beta-cariofileno, sobre o músculo liso traqueal de ratos 2012. 